\title{
FORMAÇÃO HUMANIZADA EM SAÚDE ATRAVÉS DO INCENTIVO AO HÁBITO DA LEITURA
}

\author{
HUMANIZED HEALTH \\ EDUCATION BY ENCOURAGING \\ READING HABITS
}

\section{RESUMO}

O projeto de extensão "Incentivo ao Hábito da Leitura na UFCSPA" foi uma iniciativa existente desde 2009 na Universidade Federal de Ciências da Saúde de Porto Alegre e visou cultivar o hábito da leitura de livros literários pela comunidade universitária. O projeto foi composto das seguintes ações: "Livros sem Lar", "Leituras Compartilhadas", "Leituras Compartilhadas nas Redes Sociais", "Disciplina Eletiva de Criação Literária", "Disciplina Eletiva A Roda da Vida" e "Encontro de Criação Literária e Sarau Literário", descritas neste artigo. Observou-se a utilização da literatura como meio formativo de profissionais capazes de visualizar a realidade em Saúde sob uma ótica humanizada e pautada na reflexão e no debate das padronizações institucionais e sociais, fornecendo aos alunos um processo de subjetivação, possibilitando bases críticas para a constituição do sujeito, e, finalmente, dando suporte ao discente para a compreensão dos fenômenos humanos sob variadas perspectivas e respeitando seus diversos matizes.

Palavras-chave: Literatura e saúde. Ensino na saúde. Incentivo à leitura.

\section{ABSTRACT}

The outreach project "Incentivo ao Hábito da Leitura na UFCSPA" was carried out at Federal University of Health Sciences of Porto Alegre until 2009 and its main goal was to encourage the reading of literature by the university community. The project included the following actions: "Books without a home", "Shared Reading", "Shared Reading in the Social Medias, "Elective Course on Literary Creation", "Elective Course The Wheel of Life" and "Creative Writing Meeting and Literary Soiree", all of these actions are described in this article. It was observed that the use of literature can be used to educate professionals capable of viewing reality in Health Education from a humanized perspective, based on reflection and on the debate of institutional and social standards. The project and its actions provided students with the opportunity

* Aluno de Graduação da Universidade Federal de Ciências da Saúde de Porto Alegre (UFCSPA), RS - Brasil. E-mail: andreycs@ ufcspa.edu.br

** Professora da Universidade Federal de Ciências da Saúde de Porto Alegre (UFCSPA), RS - Brasil. E-mail: lucianabp@ufcspa.edu.br 
to act as individuals, allowing critical basis for the constitution of individuals as well as the support to students to understand human phenomena under various perspectives and to respect diversity.

Keywords: Literature and health. Health education. Encouraging reading.

\section{Introdução}

É sempre muito difícil falar em leitura num país de não-leitores (LAJOLO, 2002). O Brasil está entre os países que possui menor quantidade de leitores, em contraposição a sua produção literária, que é vasta e considerável. A literatura, como uma das formas da expressão humana sobre o mundo, reflete-o e se alimenta dele num processo espiral. Sua função é bastante difícil de ser definida, tendo sido considerada como fonte de arte, na visão de Roman Ingarden, ou como um testemunho a respeito de um tempo, como Michel Foucault descreve. Nessa medida, ler o texto significa ler o mundo e decifrá-lo para compreendê-lo. Se um país não tem leitores, perde sua autonomia.

Ser letrado e ler na vida e na cidadania é muito mais que isso: é escapar da literalidade dos textos e interpretá-los, colocando-os em relação com outros textos e discursos, de maneira situada na realidade social; é discutir com os textos, replicando e avaliando posiçóes e ideologias que constituem seus sentidos; é, enfim, trazer o texto para a vida e colocá-lo em relação com ela. Mais que isso, as práticas de leitura na vida são muito variadas e dependentes de contexto, cada um deles exigindo certas capacidades leitoras e não outras. (ROJO, 2000, p. 2)

Se a leitura possibilita estabelecer relaçóes para a compreensão do mundo e de si, a literatura é o veículo ideal para essas consideraçóes. Segundo Aguiar e Bordini (1988), o livro é o instrumento que expressa conteúdo humano individual e social de forma cumulativa. A partir da leitura, o indivíduo é capaz de compreender melhor sua realidade e seu papel como sujeito nela inserido. Os textos, especialmente os literários, são capazes de recriar as informaçōes sobre a humanidade, vinculando o leitor aos indivíduos de outros tempos. Ao ler, o sujeito se transporta para outro universo, o da imaginação. Nele penetra e envolve-se, num processo de isolamento necessário para a elaboração de sua condição, inclusive de sua cidadania. A literatura amplia os horizontes e possibilita ao sujeito o alargamento de suas experiências.

A literatura corresponde a uma necessidade universal que deve ser satisfeita sob pena de mutilar a personalidade, porque pelo fato de dar forma aos sentimentos e à visão do mundo, ela nos organiza, nos liberta do caos, e, portanto, nos humaniza. Negar a fruição da literatura é mutilar a nossa humanidade (CANDIDO, 1995).

Adorno (2003) observa que o homem moderno não tem mais o que narrar, uma vez que vive num mundo em que a padronização e a mesmice imperam, e o indivíduo acha arcaica a atitude de ler um bom livro, como se isso já tivesse caído em desuso. Tendo em vista todos os benefícios que a literatura traz consigo, não seria interessante que a leitura se tornasse um hábito ultrapassado.

A leitura, nesse sentido, não deve ser vista apenas como um ato automático e desvinculado de reflexóes pessoais, pois ela também trabalha a capacidade crítica do leitor. Manguel (1997, p. 20) diz que "todos lemos a nós e ao mundo a nossa volta para vislumbrar o que somos e onde estamos. Lemos para compreender, ou para começar a compreender". O leitor não só lê palavras, como já dito, ele pensa sobre o que é lido e, dessa forma, reflete sobre sua própria realidade.

Silva (2002) afirma que, através de uma leitura crítica, o sujeito questiona as certezas oferecidas a ele como verdades institucionalizadas pela história em nossa sociedade, combatendo o conformismo, e se liberta das ideias já consolidadas. A capacidade crítica e a informação são formas de libertação e agentes promotores de autonomia. Segundo Pfitscher e Ferlini (1994, p. 87), “a informação livre e irrestrita acessível a todos é um exercício da cidadania”. As autoras vinculam diretamente a informação 
com a cidadania, porque a construção da cidadania só se dá com o acesso à informaçáo, a capacidade crítica e a autonomia, que são incentivados pela leitura. A seguinte passagem de Bamberger (2004, p. 9), "o direito de ler significa igualmente o de desenvolver as potencialidades intelectuais e espirituais, o de aprender e progredir", ilustra bem a importância da leitura.

Sabe-se que a universidade é um espaço, por excelência, de formação de cidadãos conscientes e críticos da sociedade, o que se reflete na sua competência discursiva e, por conseguinte, na sua leitura de mundo. Faz-se necessário, para isso, de um lado, formar profissionais da saúde que estejam conscientes da necessidade da promoção da leitura do texto literário e da produçáo textual, e de outro, que estes profissionais incentivem o gosto pela leitura e escrita junto aos seus pacientes, desencadeando, dessa forma, a autonomia do cidadáo como processo de busca de bem-estar e saúde.

As questóes relativas ao livro e à leitura no Brasil sáo preocupantes, tanto na quantidade como na qualidade. Enquanto na França o consumo é de 7 livros per capita/ ano e nos Estados Unidos é de 11 livros per capita/ano, no Brasil esse número é de 1,8 livros per capita/ano (segundo dados disponibilizados pelo Ibope e pela Câmara do Livro). Isso indica que é preciso fomentar açóes em todos os âmbitos da sociedade para que a leitura se torne um hábito, pois são sabidos os seus benefícios de todas as ordens, inclusive a de saúde.

Sendo a Universidade Federal de Ciências da Saúde de Porto Alegre (UFCSPA) uma instituição pública e formadora de profissionais da saúde, que possui a interdisciplinaridade como característica, era natural que projetos de incentivo à leitura fossem desenvolvidos também no ambiente universitário, pois a universidade deve comprometer-se, sobretudo, com a formação integral do profissional.

O processo interdisciplinar amplamente debatido na Literatura, conforme trazem filósofos como Foucault, Derrida e Guattari (ARAUJO, 2015), tornou-se foco de todo ambiente científico brasileiro, estendendo-se, por conseguinte, às universidades e suas práticas. Edifica-se, dessa forma, a premência das atividades de caráter globalizante no âmbito da educação brasileira; e a literatura surge como meio indiscutível dessa metodologia, na medida em que

[...] representa uma disciplina capaz de transcender o real, de transpor barreiras, de elucidar enigmas, de provocar humor e risos. Enquanto no cotidiano, o indivíduo permanece frio diante das mazelas da vida; na leitura de um romance, é capaz de desmanchar-se em lágrimas (MIRÂNDOLA; SPAZZIANI, 2004, p. 152).

\section{Seguindo-se esse raciocínio, Dias (2011, p. 3) estabelece que}

[...] trabalhos interdisciplinares são fundamentais em projetos de formação de leitores porque a literatura trata de registros de experiência humana, que é variada e se materializa nas diferentes áreas do conhecimento. Ler literatura, portanto, é ler o mundo por uma lente diferenciada, mas ela está em permanente dialogo com outras referências culturais e também científicas.

Isso permite observar que, assim como as ciências da Saúde, o trabalho da Literatura em compreender e auxiliar na edificaçáo do ser humano é intrinsecamente relacionado, já que os registros da experiência humana constituem o indivíduo e todos seus aspectos históricocontextuais, pontos essenciais na compreensão do processo saúde-doença, por exemplo. 
Nesse sentido, a Literatura como pioneira no estudo e desenvolvimento da interdisciplinaridade, demonstra-se como ferramenta diferenciada no âmbito da Saúde, para que sejam desenvolvidas atividades que englobem essa demanda. Assim, inseriu-se na universidade, como atividade contínua de extensão, o projeto de Incentivo ao Hábito da Leitura na UFCSPA, desde o ano de 2009 até o ano de 2015, tendo em vista que

As múltiplas relaçóes entre professores, alunos e objetos de estudo constroem o contexto de trabalho dentro do qual as relações de sentido são construídas. Nesse complexo trabalho, o enfoque interdisciplinar aproxima o sujeito de sua realidade mais ampla, auxilia os aprendizes na compreensão das complexas redes conceituais, possibilita maior significado e sentido aos conteúdos da aprendizagem, permitindo uma formação mais consistente e responsável (THIESEN, 2008, p. 551).

Dessa forma, estabeleceu-se o projeto supracitado, que possuía como objetivo principal promover o hábito da leitura pela comunidade universitária da UFCSPA, e como alguns dos objetivos secundários: a) estimular o conhecimento da teoria da literatura e das formas de escrita literária; b) manter o hábito da leitura de textos literários; c) estabelecer relaçóes entre a leitura e a saúde e; $d$ ) promover a solidariedade através da campanha de doação de livros. Os objetivos descritos foram desenvolvidos através das açóes previstas no projeto, e que serão descritas a seguir.

\section{Metodologia}

Desde 2009, o projeto foi avaliado anualmente pela Pró-Reitoria de Extensão e Assuntos Comunitários (PROEXT) da UFCSPA, sendo contemplado com uma bolsa de extensão de duração anual, em todos os anos de sua duração, a partir do Programa de Bolsas de Extensão (PROBEXT), existente na Universidade. Conforme sugere o título do projeto, as açóes foram elaboradas com ocorrência no Campus Central da UFCSPA, tendo como público-alvo a comunidade acadêmica da Universidade. Isso não exclui, no entanto, a participação da comunidade externa, como será explicitado posteriormente. Dentre as açôes desenvolvidas estão as seguintes: "Livros sem Lar", "Leituras Compartilhadas", "Leituras Compartilhadas nas Redes Sociais", "Disciplina Eletiva de Criaçấo Literária", "Disciplina Eletiva A Roda da Vida", "Encontro de Criação Literária e Sarau Literário".

Com o entendimento de que a leitura também pode ser curativa, a açáo "Livros sem Lar" trabalhou com o objetivo de incrementar a interação entre os leitores e os livros de forma livre e não padronizada, a partir da disponibilização de obras doadas em estantes dentro do campus, que podiam ser acessadas por qualquer membro da comunidade de forma autogestionada, transcendendo ao modelo tradicional das bibliotecas. Para isso, a metodologia foi dividida em diferentes etapas: campanhas permanentes de doação de livros para o projeto pela comunidade da UFCSPA, catalogação dos livros, organização dos livros nas prateleiras, divulgaçáo constante da ação e acompanhamento do projeto, com tabulaçáo de dados quantitativos.

Pela ótica da socialização de leituras, a ação "Leituras Compartilhadas" ocorreu entre os anos de 2009 e 2013, estruturando-se como um encontro aberto à comunidade acadêmica para o debate de uma obra literária que se relacionasse com questôes de Saúde. Previamente, era divulgada a obra a ser discutida, e na data marcada, reuniam-se os participantes voluntários para compartilhar suas impressóes daquela leitura e relacioná-la 
com sua prática profissional, com a sociedade e com outras experiências, guiados pelos comentários iniciais de profissionais da área da Saúde ou não, que eram convidados previamente com o objetivo de comentarem a obra e incentivarem novas interpretaçóes sobre ela.

Observando-se a possibilidade de expandir o alcance da discussão de obras literárias, optou-se, a partir de 2014, por modificar a metodologia da açáo anterior, estabelecendose a ação "Leituras Compartilhadas nas Redes Sociais", que englobou uma página na plataforma Facebook e outra na plataforma Blogspot. Essas ferramentas objetivavam realizar postagens sobre autores, obras, eventos de interesse, notícias e outros textos relevantes, também almejando divulgar produçóes escritas de membros da comunidade interna e externa à UFCSPA que assim o desejassem.

Por entender que a escrita literária conforma possibilidade de expressão do sujeito em seu entorno também como veículo propulsor de bem-estar, em seu trabalho com a saúde/doença, a ação "Disciplina Eletiva de Criação Literária" desenvolveu-se por dois anos no cenário universitário. Tendo sido pela primeira vez ofertada no segundo semestre de 2013, edificou-se como um espaço de construção e debate da escrita literária como fonte de expressão do sujeito em relação ao seu meio, na medida em que é cada vez mais necessário que se proponha, no campo da Saúde, uma interaçáo multidisciplinar das ciências, por exemplo.

A açáo desenvolveu-se semestralmente, das seguintes formas: as aulas eram expositivas e dialogadas, com o uso das novas tecnologias de ensino para a educação superior (seminários, simpósios, palestras, filmes e outros); foram utilizados, quando necessário, recursos audiovisuais; os alunos participavam dos seminários e debates através da leitura prévia e da discussão de textos selecionados, assim como a escrita dos textos literários. Desse modo, houve o desenvolvimento de atividades práticas, pretendendo-se que os alunos exercitassem a escrita literária conforme visto teoricamente nas aulas da disciplina e como forma de depósito de emoçóes e reflexôes sobre sua prática profissional em Saúde.

A ação "Disciplina Eletiva A Roda da Vida" objetivou discutir temas das Ciências e da Saúde a partir de textos literários, numa abordagem interdisciplinar, além de construir uma visão abrangente da atuação profissional e ampliar a habilidade de trabalho multidisciplinar. A ação, que se desenvolveu no segundo semestre de 2015, ocorreu semanalmente, em um encontro de duas horas, nos ambientes de sala de aula e em laboratórios, contando sempre com a participação de docentes de áreas diversas da universidade. As aulas eram expositivas e dialogadas, com o uso das novas tecnologias de ensino para a educaçáo superior (seminários, simpósios, palestras, filmes e outros). Foram utilizados, quando necessário, recursos audiovisuais. Os alunos participaram dos seminários e debates com professores especialistas das abordagens temáticas através da leitura prévia e da discussão de textos selecionados.

Pretendendo incentivar tanto a leitura como a criação de textos literários, desenvolveu-se o Encontro de Criação Literária. O público-alvo desse evento constituiuse de membros da comunidade interna e externa da UFCSPA que tivessem interesse por escrita literária e gostassem de escrever esse tipo de texto. Os participantes foram organizados em grupo reduzido, de cerca de dez membros. Para a inscriçãa, era necessário que o candidato submetesse um escrito de sua autoria, permitindo, dessa forma, a seleção dos participantes conforme o escopo do público-alvo. O Encontro de Criaçáo Literária 
compôs-se por três dias de evento, cada qual com duas horas. Nesses dias, foram debatidos textos e apresentadas informaçóes sobre a criação literária aos participantes. Juntamente do Encontro de Criação Literária, foi organizado um Sarau Literário, com o intuito de promover um espaço de troca e divulgação das produçôes literárias do evento.

\section{Resultados}

$\mathrm{Na}$ ação "Livros sem Lar", desde seu início, em 2009, até o mês de dezembro de 2015, já haviam sido doados ao projeto 1.488 livros, dos mais diversos gêneros, línguas e temáticas; desses, estavam na estante apenas 120 obras; dessa forma, foram retirados 1.368 livros. Transcendendo-se a esses resultados quantitativos, observou-se o engajamento e a interação da comunidade com a proposta, que, apesar da ousadia em sua dinâmica e concepção, foi assimilada pela comunidade, que, ao retirar um livro e distribuí-lo em seus círculos, auxiliou na promoção do hábito da leitura.

$\mathrm{Na}$ ação "Leituras Compartilhadas", foram desenvolvidos ao todo 12 encontros: um em 2009, três em 2010, quatro em 2011, quatro em 2012 e um em 2013. Os títulos foram escolhidos pelos participantes do projeto a partir das leituras realizadas por eles e da relevância que a temática do livro pode ter para uma discussão que possa articular o tema da Literatura com a Saúde. Foram escolhidos os livros "Leite Derramado" (Chico Buarque), "Carta ao Pai" (Franz Kafka), "A Majestade do Xingu" (Moacyr Scliar), "Noite" (Érico Veríssimo), "Operação Portuga: Cinco Homens e um Recorde a Ser Batido" (Sérgio Xavier), "O Fim do Meu Vício" (Olivier Ameisen), "Ensaio Sobre a Cegueira" (José Saramago), "O Centauro no Jardim” (Moacyr Scliar), "Antes do Baile Verde” (Lygia Fagundes Telles), "Mortalha para uma enfermeira" (P. D. James), "Colecionador de Lágrimas" (Augusto Cury) e "Cromossomo 6" (Robin Cook), aqui listados em ordem cronológica de acontecimento do encontro. Distribuídos entre esses encontros, foram computados, ao mínimo, 113 participantes.

$\mathrm{Na}$ ação "Leituras Compartilhadas nas Redes Sociais", o blog "Leituras na UFCSPA" contou com 1.823 visualizaçóes até dezembro de 2015, sendo realizadas cerca de 50 postagens desde a sua criação, em 8 de julho de 2010. A página "Leituras Compartilhadas" da plataforma Facebook possui mais de 140 postagens, e cerca de 75 "curtidas". Nessa ação, grande parte das pessoas envolvidas era da comunidade externa à Universidade. Na ação "Disciplina Eletiva de Criação Literária", foram abarcados pela disciplina um total de 15 alunos da UFCSPA, distribuídos nos três anos de ocorrência da atividade até 2015 . Neste período, mais de 50 produçóes foram apresentadas, sendo relacionadas aos gêneros conto, poesia e crônica, por exemplo. Os temas abordados representavam uma interessante diversidade, que ia desde o trabalho com as mazelas do ser humano até um pequeno evento de carnaval. Todos acabavam recheados de surpresas ao leitor, pois traziam consigo a forte influência da discussão sobre a teoria da literatura e suas implicaçóes sobre a criação literária.

Assim sendo, as ricas produçóes dos alunos foram uma pequena representação de todo o empenho na elaboraçáo de uma atividade que fomente a leitura e a escrita como formação complementar, mas essencial, dos profissionais da Saúde na instituição. Todas as produçóes, ao fim do curso, eram revisitadas na estruturação de um sarau, que cresceu em conteúdo e qualidade a cada edição. 
$\mathrm{Na}$ ação "Disciplina Eletiva A Roda da Vida", contou-se com a participaçáo de 13 discentes de diversos cursos de graduação da universidade, e observou-se o desenvolvimento de novas formas de visualizar a realidade e a prática profissional em Saúde, sob uma ótica interdisciplinar e reflexiva, pautada na crítica e no debate das relaçóes existentes nos futuros ambientes de exercício da profissão, dando suporte ao discente para a compreensão de um fenômeno sob variadas perspectivas e respeitando seus diversos matizes.

$\mathrm{Na}$ ação "Encontro de Criação Literária e Sarau Literário", observaram-se, nos dois anos de ocorrência, 20 participantes apenas no Encontro, e 74 participantes nos dois eventos, além dos palestrantes e da equipe executora da atividade. No ano de 2014, os três dias de Encontro foram conduzidos pelos professores doutores Pedro Dutra Gonzaga, Gabriela Farias da Silva e Viviane Viebrantz Herchmann, os quais elaboraram oficinas sobre o conto, a poesia e a crônica, respectivamente. Nesse ano, o Sarau Literário contou com a participação dos alunos do Curso de Gastronomia da UFCSPA, que produziram pratos inspirados em trechos de obras literárias, como da crônica "O Ovo", de Luiz Fernando Veríssimo, da poesia "País do Açúcar", de Carlos Drummond de Andrade, ou do romance "Cem Anos de Solidão", de Gabriel García Márquez. Além disso, o Coral UFCSPA participou do evento com algumas de suas vozes durante a apresentaçáo de obras do Encontro ou prato elaborado pelos discentes de Gastronomia.

No ano de 2015, elaborou-se o Encontro de Criaçáa Literária, visando-se englobar todos esses núcleos que participaram da ediçáo anterior, de forma que foi proposta a temática "Sons e Sabores" para o evento. Assim, no primeiro dia, instigou-se os participantes a produzirem haikais dentro dessa temática, acompanhados da escritora Nilva Ferraro. Após a instruçáo inicial, no segundo dia a questáo do sabor foi trabalhada com a professora mestra Tainá Bacellar Zaneti, que incluiu em sua temática a "Amazônia", inserindo elementos da culinária da regiáo. Ao terceiro dia, o maestro do Coral UFCSPA, Marcelo Rabello dos Santos, auxiliou os participantes a musicarem seus haikais e a construírem um haikai musicado de todos os participantes. Essas obras foram divulgadas no Sarau Literário, conforme acontecido no ano anterior. Novamente, alunos do curso de Gastronomia participaram do evento. Dessa vez, utilizando-se do tema "Amazônia" para a produção de pratos típicos da regiấo.

\section{Conclusóes}

Em seus seis anos de existência, o Projeto de Incentivo ao Hábito da Leitura na UFCSPA trouxe valiosas contribuiçóes à Universidade. Constituído de atividades diversificadas e renovadas a cada ano, puderam ser elaborados espaços de debate, construção e crítica do hábito da leitura junto dos alunos da instituição e da comunidade externa. Assim, processos de discussáo humanizada da saúde, como o promovido por essas açóes, demonstram-se fundamentais para a construçáo de um currículo náo apenas abrangente, mas que também esteja direcionado à formação integral dos profissionais da área. Nesse sentido, a UFCSPA tem, de forma pioneira, promovido esses aspectos, tendo em vista o fato de que adotou as açóes do projeto como integrante da área de Extensão e, dessa forma, incorporou grande parte das atividades oferecidas em sua agenda cultural, 
demonstrando interesse na edificação de seus alunos de forma interdisciplinar e voltada à formação cidadã e consciente.

Isso permite observar que, além de promover o hábito da leitura, o projeto também se dedicou, de forma indireta, ao combate do mecanicismo e da "hiperespecializaçáo" dos profissionais da ciência em geral, e nesse caso, especialmente, da área da Saúde, na medida em que construiu espaços de integração entre discentes de áreas como a Biomedicina, Fonoaudiologia, Medicina, Nutrição e Psicologia, desses alunos com docentes da Literatura, da Música, da Biologia e da Gastronomia, e por fim, de todos esses atores com membros da comunidade externa à universidade. Além disso, proporcionou-se o desenvolvimento da capacidade de observar fenômenos cotidianos de forma holística, ultrapassando-se os limites disseminados pelos manuais de anatomia.

Os aspectos supracitados podem ser contemplados quando se observa, por exemplo, o engajamento e a interação da comunidade com a proposta "Livros sem Lar", que apesar da ousadia em sua dinâmica e concepção, foi assimilada pela comunidade, que, ao retirar um livro e distribuí-lo em seus círculos, auxiliou na promoçáo do hábito da leitura, promovendo a interação entre os leitores e os livros de forma livre e não-padronizada na universidade e fora dela. Ainda observando o quesito interação, é importante salientar o alcance das açóes "Leituras Compartilhadas" e "Leituras Compartilhadas nas Redes Sociais", ao passo que promoveram o hábito da leitura além dos limites do campus da UFCSPA, prestando-se ou a trazer leitores da comunidade para a universidade ou a chegar até os leitores através das mídias digitais.

A "Disciplina Eletiva de Criação Literária" proporciona uma reflexão mais aprofundada, tendo em vista a riqueza de seus resultados. Inicialmente, pontua-se que "a criação literária, como experiência do real, evidencia a potência constituinte do trabalho vivo no processo de subjetivaçáo" (FERREIRA, 2011, p. 7). Pretende-se debater aqui a capacidade da criação literária de edificar no ser humano processos de autoconhecimento que o auxiliam em sua construção pessoal. Isso pode ser explicitado pelas habilidades de construção de escrita e de compreensão de realidades que foram observadas nos textos elaborados.

Desafiados à construçáo de um conto que abordasse as temáticas saúde e pobreza, por exemplo, os alunos desenvolveram produçôes que se assemelhavam às dos cânones da literatura clássica. Dotadas de realidade, simplicidade e agudeza de sensaçóes, pôdese apreciar a excelência de textos carregados com reflexóes sobre problemas sociais e sanitários do contexto, fortemente embasados nas discussóes de teoria da literatura realizadas na disciplina. Neste sentido, foi possível observar essa desconstrução dos enunciados estabelecidos do eu, que são colocados ao crivo da crítica, promovendo-se um desafio aos conhecimentos e saberes adquiridos nas relaçóes com as ordens institucionais e sociais normatizadas.

Colabora-se, dessa forma, para uma constituição do sujeito pautada para a discussão e produçáo de sentidos para a existência humana e as adversidades do mundo. Assim, emerge de modo interessante a disponibilidade da disciplina no âmbito universitário, à proporçáo que o meio acadêmico se pauta como celeiro de opinióes e de novas ferramentas para a sociedade, pois, neste sentido, demonstrou-se nos alunos a capacidade de articular seus conhecimentos literários com as relaçóes humanas e sociais.

Para além da disciplina em si, vê-se nos alunos egressos a capacidade de desenvolver sua profissáo cada vez mais relacionada à ótica humanista atualmente preconizada 
na formação de profissionais de saúde, já que, apenas podendo se estar aberto ao conhecimento de diferentes realidades se é capaz de compreender as subjetividades de seus futuros pacientes, que não vão apenas carregar consigo um processo de doença, mas estaráo intrinsecamente ligados a seus aspectos histórico-contextuais, essenciais na concepção dos quadros clínicos de uma enfermidade.

Conforme citado anteriormente, na "Disciplina Eletiva A Roda da Vida" também se presenciou o desenvolvimento de novas formas de visualizar a realidade e a prática profissional em Saúde, sob uma visáo interdisciplinar e reflexiva, pautada na crítica e no debate das relaçóes existentes nos futuros ambientes de exercício da profissáo, dando suporte ao discente para a compreensáo de um fenômeno sob variadas perspectivas e respeitando seus diversos matizes.

Por fim, em semelhante perspectiva, o "Encontro de Criação Literária e Sarau Literário" proporcionou aos participantes a associaçáo de aspectos compositivos da leitura e escrita à compreensão de que a literatura é a expressão do humano na forma escrita, destarte, relacionando-se os conhecimentos da área da Saúde à expressão artística do autor como representação da sociedade. Partindo deste pressuposto, estabelece-se não só o enriquecimento cultural do leitor, mas seu aperfeiçoamento profissional, a partir da experiência literária. Sugere-se que novos projetos sejam desenvolvidos náo somente nos ensinos fundamental e médio no país, mas também que o ensino superior se volte para a formaçáo integral dos profissionais, de forma a manter, atualizar ou florescer nos acadêmicos o gosto pela leitura e o conhecimento de seus benefícios.

\section{Referências}

ADORNO, T. L. W. Notas de literatura I. 34. ed. Tradução: Jorge de Almeida. São Paulo: Duas Cidades, 2003.

AGUIAR, V. T.; BORDINI, M. G. Literatura: a formação do leitor - alternativas metodológicas. Porto Alegre: Mercado Aberto, 1988.

ARAUJO, M. C. A literatura vista da margem: os heróis pós-estruturalistas. Revista Espaço Acadêmico, Maringá, v. 14, n. 165, p. 91-97, fev. 2015. 
BAMBERGER, R. Como incentivar o hábito da leitura. São Paulo: Ática, 2004.

CANDIDO, A. Vários escritos. 3. ed. São Paulo: Duas cidades, 1995.

DIAS, C. A. O papel da interdisciplinaridade na formação do leitor literário. In: CONGRESSO INTERNACIONAL DE LEITURA E LITERATURA INFANTIL E JUVENIL, 3., 2008, Porto Alegre. Anais... Porto Alegre: PUCRS, 2009.

FERREIRA, J. B. 0 poder constituinte do trabalho vivo: análise psicodinâmica da criação literária. 203 fl. 2011. Tese (Doutorado em Psicologia) - Instituto de Psicologia, Universidade de Brasília, Brasília, 2011.

LAJOLO, M. Do mundo da leitura para a leitura do mundo. São Paulo: Ática, 2002.

MANGUEL, A. Uma História da Leitura. São Paulo: Companhia das Letras, 1997.

MIRANDOLA, S. M. M.; SPAZZIANI, M. L. A Literatura como gerador de novos significados. Revista Nucleus, Ituverava, v. 2, n. 1, p. 159-166, abr./out., 2004.

PFITSCHER, E. F.; FERLINI, M. A. P. M. Bibliotecário, informação e cidadania. Revista Interamericana de Biblioteconomia, Medellín (Colômbia), v. 17, n. 2, p. 85-89, jul./dez. 1994.

ROJO, R. (Org.). A prática de linguagem em sala de aula: praticando os PCNs. São Paulo: EDUC, 2000.

SILVA, E. T. 0 ato de ler: fundamentos psicológicos para uma nova pedagogia da leitura. São Paulo: Cortez, 2002.

THIESEN, J. S. A interdisciplinaridade como um movimento articulador no processo ensino-aprendizagem. Revista Brasileira de Educação, Rio de Janeiro, v. 13, n. 39, p. 45-598, set./dez. 2008. 